\section{SP5-2 IDENTIFYING A HIDDEN PROBLEM-DEMENTIA- IN ELDERLY PEOPLE LIVING IN OLD-AGE HOMES}

doi:10.1136/jech.2011.142976p.38
Nagaraja,* M A Khan, G Bhat. MMC \& RI, Karnataka, India

Objective To identify dementia in geriatric people living in old-age homes and to study the risk factors of dementia in them.

Material and Methods Setting:-Eight old-age homes in Mysore City were selected at random.

Inclusion Criteria The inmates of the old-age homes aged above 60 years staying in the old-age home for atleast 2 months were included in the study.

Collection of Data Mini Mental State Examination (MMSE) was done to screen the subjects $(n=100)$ and those with score $<23$ are considered to have dementia $(n=24)$. To these 24 subjects Blessed Dementia Rating Scale was used.

Results

- Females $(29.4 \%)$ showed more signs of dementia than males $(12.5 \%)(\mathrm{p}<0.05)$

- More people in the age group 71-80 years had dementia (20\% of males, $46.2 \%$ of females) $(p<0.001)$

- Females who had both hypertension and diabetes mellitus showed dementia in more number (50\% being affected).

Conclusion Among the 100 subjects studied 24 were found to have dementia, with higher incidence in females. Occurrence of dementia increased with age and it was higher in female subjects with both diabetes mellitus and hypertension.

\section{SP5-3 PSYCHOSOCIAL PROFILE OF INMATES OF JUVENILE HOMES IN MYSORE: A PILOT STUDY}

doi:10.1136/jech.2011.142976p.39

V Nagaraja, ${ }^{*}$ M A Khan, G Bhat. MMC \& RI, Mysore, Karnataka, India

Background A "Delinquent" refers to a child who has been neglected and abandoned by parents and who indulges in wrongful activities. Juvenile delinquency is a social problem worldwide of which less is acknowledged and much less is understood.

Aim This study examined the sociodemographic, psychological and self-esteem issues among the inmates of juvenile homes.

Methods A structured questionnaire was used to interview 129 juveniles residing in juvenile homes. Self-esteem and Psychological health of the juveniles were scored using Rosenberg's Self-esteem scale and General psychological well-being scale respectively. Personal hygiene was scored using a validated scale. Data were analysed using SPSS statistical software version 17

Results Majority of the inmates (90\%) were in the age group of $7-16$ yrs. The duration since admission positively correlated with the Psychological well-being score $(r=0.184, p=0.037)$ and Personal hygiene score $(\mathrm{r}=0.254, \mathrm{p}=0.004)$. Rosenberg Self-esteem score $(r=0.228, p=0.01)$ and Psychological Well-being score $(r=0.204$, $\mathrm{p}=0.02$ ) also positively correlated with Personal hygiene score. Girls had higher Psychological well-being score $(p=0.016)$ and Personal hygiene score $(p=0.001)$. Interestingly, boys wanted to join parents back more than girls $(p<0.05)$. Girls wanted to take up higher education more than boys $(p<0.05)$.

Conclusions Our study concluded that the Psychological health and Personal hygiene of the children improved with the duration of stay at the juvenile home. Film stars and Television have maximum impact on them implying these could be utilised as modes of operant conditioning (modelling) to reinforce positive behaviours in these children.

\section{SP5-4 AN ECOSOCIAL ASSESSMENT OF TUBERCULOSIS AMONG MEXICAN MIGRANTS INDIGENES IN SONORA, MEXICO}

doi:10.1136/jech.2011.142976p.40

${ }^{1} \mathrm{G}$ Alvarez, ${ }^{*} \mathrm{M}$ del Carmen Candia, ${ }^{1} \mathrm{M}$ E Reguera, ${ }^{2} \mathrm{M}$ B Rivera, ${ }^{3} \mathrm{~T}$ Weaver ${ }^{3} \mathrm{~J}$ Greenberg. 'Universidad de Sonora, Hermosillo, Sonora, Mexico; ${ }^{2}$ Secretaría de Salud Pública, Hermosillo, Sonora, Mexico; ${ }^{3}$ University of Arizona, Tucson, Arizona, USA

Introduction Tuberculosis (TB) is a challenge for the Mexican Health System. Its burden is particularly high among migrants indigenes. Cultural barriers aggravate vulnerability of these groups that travel along the "Mexican Pacific Corridor" to get jobs in Sonora, and eventually will migrate to the United States. Little is known about how perceptions of disease, barriers to care, marginalisation, and migration history, relate to the TB burden of these communities.

Methods We conducted a cross-sectional study to examine the TB incidence in Mexican migrant indigenes assented in agricultural fields of Sonora, Mexico. The epidemiological profile of TB was characterised, and a qualitative approach was used to examine perceptions of health personnel, and TB patients.

Results A fourfold excess of TB incidence rate (121.2/100 000) was found in these groups when compared with national and state average. Very low rates of cure $(25 \%)$ were found in indigenes, and a high proportion $(54 \%)$ of TB patients was detected belatedly. A mixture of indigenes patients was observed, most of them coming from the south of Mexico. TB burden may be underestimated in these groups because ethnicity is not routinely investigated by health personnel.

Conclusions The TB burden among Mexican migrant indigenes arriving to Sonora is well above of the national average. The Mexican Health System does not systematically identify ethnicity in TB patients, which may exacerbate difficulties for the TB control, and eventually to favour its dissemination along the US-Mexico Border.

\section{SP5-5 RISK FACTORS ASSOCIATED WITH BORDERLINE INTELLIGENCE IN SCHOOLCHILDREN: A CASE-CONTROL STUDY}

doi:10.1136/jech.2011.142976p.41

${ }^{1} \mathrm{~A}$ Afkhamzadeh, ${ }^{* 2} \mathrm{~A}$ Delpisheh, ${ }^{1} \mathrm{~N}$ Esmailnasab. ${ }^{1}$ Kurdistan University of Medical Sciences, Sanandaj/Kurdistan, Iran; ${ }^{2}$ llam University of Medical Sciences, Ilam/llam, Iran

Objective To determine risk factors associated with borderline intelligence during intra-uterine life, delivery and the neonatal periods.

Methods In a case-control study, 200 year one schoolchildren aged 6 years were recruited. A standard IQ test was used for psychometric testing. Cases had a borderline intelligence (75-84 scores) and normal controls had an IO of 85 or above scores. Cases and controls were matched for gender.

Results Regression analysis showed that mother's illiteracy (Adjusted OR 2.7, 95\% CI 1.6 to 4.2, $\mathrm{p}=0.001$ ), familial history of mental retardation (AOR 2.1, 95\% CI 1.4 to $3.5, \mathrm{p}=0.002$ ) and maternal drug consumption during pregnancy (AOR 1.7, 95\% CI 1.1 to $2.5, \mathrm{p}=0.003$ ) were the main adjusted risk factors associated with borderline intelligence in childhood. No significant association was found between adverse birth outcomes including low birth weight and prematurity and borderline intelligence in children.

Conclusions IQ of schoolchildren is affected by both prenatal and postnatal factors as well as social determinants such as parental education. Controlling these factors has important implications for preventive strategies in psychological, maternal and child health programs worldwide. 